\title{
CXXXV. STUDIES IN PHOTOSYNTHESIS.
}

\section{THE FORMALDEHYDE HYPOTHESIS.}

\author{
BY EUSTACE CECIL BARTON-WRIGHT \\ AND MONTAGU CAMDEN PRATT. \\ From the Botany Department, King's College, Strand, W.C. 2.
}

(Received June 23rd, 1930.)

\section{INTRODUCTION.}

Since 1870, when Baeyer put forward the suggestion that formaldehyde was the first stage in the photosynthetic process in the green leaf and that this substance was subsequently polymerised to reducing sugars, numerous investigators have from time to time attempted to test the validity of this hypothesis and in the main have pronounced in its favour on no very convincing evidence.

The experimental work on this aspect of plant physiology has been conducted along several different lines, such as feeding plants with formaldehyde or its derivatives, or testing leaves for formaldehyde, and also by means of in vitro experiments.

According to Loew [1889] and Bokorny [1891] the alga Spirogyra, when fed with the sodium bisulphite compound of formaldehyde, forms starch, while Boitreux [1920] and Moore and Webster [1920] have put forward the claim that Trichoderma viridis can assimilate free formaldehyde. A similar claim was made for the higher green plants some years previously by Baker [1913] and also by Grafe and Vieser [1909, 1911] provided that the concentration of the aldehyde was not too high and that there was sufficient illumination. On the other hand, formaldehyde vapour readily oxidises in the air to give formic acid, so that if these results prove anything at all they show that formic acid is the first product of photosynthesis.

The utilisation of a compound by a leaf is no proof that it forms an intermediate stage in its metabolic activities, and a large number of substances are now known, such as glycerol, which can be used by the green leaf for the preparation of starch.

The difficulty of obtaining convincing proof of the truth of the formaldehyde hypothesis has led to the adoption of in vitro experiments. Baly [1921, 1927, 1929], who is at present the chief investigator in this particular field of photosynthesis, claims that the processes in vitro and in vivo are similar. $\mathrm{He}$ states that when solutions of carbon dioxide are exposed to ultra-violet radiation 
appreciable amounts of formaldehyde are produced, and further asserts that if a coloured catalyst, such as cobalt or nickel carbonate, be present, this process takes place in ordinary light with the production of reducing sugars. This latter change, i.e. when coloured catalysts are present, is said to proceed at a rate directly proportional to rise of temperature for the lower range of temperature values $\left(5-31^{\circ}\right)$, but this proportionality ceases above $31^{\circ}$, and there is a rapid decrease in yield. For a complete review of this work see Barton-Wright [1930].

The chief disability under which the formaldehyde hypothesis labours is that this compound is highly toxic to the living cell, and if it were produced in any quantity would quickly cause death. This difficulty has been answered by the assumption that the formaldehyde is polymerised as fast as it is produced, while Baly considers that the ordinary form of the aldehyde, $\mathrm{H}-\mathrm{C}_{\mathrm{H}}^{\mathrm{O}}$, is not produced in the process, but that the tautomeric, or, as he prefers to call it, "active" aldehyde, $\mathrm{H}-\mathrm{C}-\mathrm{OH}$, is formed, and it is on this account that it cannot be detected by the usual tests.

The most convincing evidence for the validity of the formaldehyde hypothesis appeared in a recent paper by Klein and Werner [1926]. These investigators employed the reagent dimedon (dimethylhydroresorcinol) which has been so successfully used by Neuberg and his co-workers in their work on the elucidation of the chemical mechanism of alcoholic fermentation.

Dimedon forms a delicate test for aldehydes and readily reacts with these bodies to give insoluble condensation products.

With formaldehyde and acetaldehyde the reaction is particularly delicate, and we have been able to detect as small amounts of formaldehyde as 1 part in 100,000 of water. Moreover, it is a simple matter to distinguish between formaldomedon and acetaldomedon, since these condensation products differ in crystal form and melting point.

Klein and Werner employed a number of different plants in their experimental work, aquatics such as Elodea canadensis, Myriophyllum (sp.), Potamogeton and others, and also ordinary mesophytes and succulents.

In the case of aquatics, the plants were placed in flat dishes containing nutrient solution together with $10-20 \%$ of calcium bicarbonate to supply carbon dioxide, and dimedon in concentration of 1 in 1000 was then added. This proportion of dimedon was said to reduce only slightly the assimilation rate. With mesophytes, cut shoots were placed in the shorter arm of an unequal U-tube and a solution of dimedon ( 1 in 2000) was forced through the stem by means of a mercury column. It was discovered that the dimedon had a narcotic effect on the leaves and apparently caused the stomata to close. The latter were kept open artificially by means of a $0.1 \%$ solution of sodium chloride. In succulents, such as Sempervivum, the dimedon solution was directly injected into the assimilating tissues by means of a Pravz syringe. Here again the stomata tended to close and were kept open by the addition of weak sodium chloride solution. It was found that stronger solutions of 
dimedon ( 1 in 200 and 1 in 500) could be used with succulents without materially reducing the rate of assimilation.

The most extensive experiments, however, were conducted with aquatics, especially Elodea canadensis. The plants were placed in flat dishes in the manner described above, together with nutrient medium containing calcium bicarbonate and dimedon, and allowed to assimilate for a period of 6-8 hours under a constant light intensity of 40,000-100,000 lux at a temperature of $20^{\circ}$. The condensation product of formaldehyde and dimedon (formaldomedon) was then detected in the external solution and little was found in the plants themselves.

It was ascertained that formaldomedon was only produced in the light and in the presence of carbon dioxide. In the dark, acetaldomedon was formed instead. Again, narcotics, such as potassium cyanide and phenylurethane, in dilute concentration, prevented the production of formaldomedon, and only a very small amount of acetaldomedon was produced.

This work appeared to lend definite support to a long-standing hypothesis. It therefore appeared necessary to us to confirm it in every particular, more especially as we could not understand why the formaldomedon was principally present in the external medium, so far as aquatics were concerned, and only a trace was to be found in the assimilating cells. A further point that made repetition necessary was the fact that nowhere throughout the course of their investigation did Klein and Werner make any attempt to control the $p_{\mathrm{H}}$ of their medium -an important point in an investigation of this nature. We have accordingly repeated this work and the results are recorded below.

\section{Experimental.}

The plant used in this investigation was Elodea canadensis, which was collected from a pond at Greenford, Middlesex, and kept in large tanks in Knop's medium diluted to 1 in 20, together with some mud from the bottom of the pond. The tanks were kept continuously aerated by a special device. With this arrangement the plants remained in a perfectly healthy condition and grew vigorously.

Preparation of dimedon. The dimedon was prepared by Vorlander's [1893] method with only slight modification.

Narcotic effect of dimedon on assimilation. Klein and Werner have stated that dimedon has a narcotic action on the rate of assimilation, but they give no exact figures for this depressant effect. The matter was quantitatively investigated here by means of a Wilmott's "bubbler." Cut shoots were placed in Knop's solution (previously diluted to 1 in 20 ), containing $0.6 \%$ of sodium bicarbonate and exposed to a light intensity of 1400 candle-power at a distance of 2 feet. Excess of heat rays was removed by a water screen and the temperature was maintained at $19^{\circ} \pm 1$. In each experiment the shoot was allowed to assimilate normally for 2 hours and then the necessary amount of dimedon was added and the fall in the rate of assimilation observed. A representative experimental result is given in Table $I$. 


\begin{tabular}{ccc} 
& \multicolumn{2}{c}{ Table I. } \\
Time & $\begin{array}{c}\text { Bubbles } \\
\text { per min. }\end{array}$ & \\
11.00 a.m. & - & Culture solution, $0.6 \% \mathrm{NaHCO}_{3}$ alone \\
11.30 a.m. & 41 & \\
12.00 & 41 & \\
12.30 p.m. & 40 & Dimedon added $(0 \cdot 1 \%)$ \\
1.00 p.m. & 41 & \\
1.30 p.m. & 31 & \\
2.00 p.m. & 30 & \\
2.30 p.m. & 29 & \\
3.00 p.m. & 33 & \\
3.30 p.m. & 34 & \\
$p_{\text {H }}$ of solution $7 \cdot 4$ &
\end{tabular}

In every case that was tried it was discovered that the addition of dimedon produced a markedly depressant effect on the rate of assimilation.

Klein and Werner state that dimedon reduced the $p_{\text {H }}$ of their nutrient medium (the nature of which they do not state) from 8.0 to 4.5 . We found that a $0.1 \%$ solution of dimedon reduced the $p_{\text {H }}$ of Knop's solution containing $0.6 \%$ of sodium bicarbonate from 8.6 to $7 \cdot 4$. In all subsequent work, therefore, the $p_{\mathrm{H}}$ of our various culture media was maintained at this latter value by suitable buffering.

For the actual experimental work dealing with the alleged production of formaldehyde, Klein and Werner's methods were closely followed. A number of shoots of Elodea, approximately $10 \mathrm{~cm}$. long, were cut and placed in flat dishes with the Knop's mixture containing bicarbonate and dimedon, and exposed to a constant light intensity of 1400 candle-power for 6-8 hours at a distance of $18 \mathrm{in}$. Excess of heat rays was removed by suspending between the source of light and the plants a water screen through which a continuous stream of water was maintained. With this arrangement the temperature remained at $20^{\circ} \pm 1$ for the whole experimental period. The $p_{\mathrm{H}}$ of the medium was tested every hour and was brought back to $\mathbf{7 \cdot 4}$ by the addition of a suitable amount of buffer $\left(p_{\mathrm{H}} 2 \cdot 6\right)$. A control experiment was run in the dark, the $p_{\mathrm{H}}$ again being kept at $\mathbf{7 \cdot 4}$. We deviated, however, from Klein and Werner at this stage, in that we also exposed to light under the same conditions a nutrient solution containing bicarbonate and dimedon, but no plant, and a similar solution was placed in the dark.

At the end of the assimilation period, the procedure described by Klein and Werner was followed. A little sodium carbonate was added to the nutrient solutions to insure that all the formaldomedon had passed into solution, as this substance is very insoluble in acid or neutral media, but is readily soluble in alkaline solutions. The solution was then filtered and acidified with hydrochloric acid and extracted with light petroleum (100 cc. to 1 litre of solution) for several hours on a mechanical shaker. The solvent was separated and twice washed with a saturated solution of sodium chloride and evaporated to dryness under reduced pressure at $40^{\circ}$. A mass of white crystals was obtained. This consisted of a mixture of dimedon and formaldomedon in the case of plants 
exposed to light and, according to Klein and Werner, unchanged dimedon and acetaldomedon for plants that had been allowed to remain in the dark.

To separate the condensation product from unchanged dimedon, Klein and Werner dissolved the crystalline residue in $3 \mathrm{cc}$. of a $10 \%$ solution of potassium carbonate and then slightly acidified with phosphoric acid. This mixture was placed in a small retort and distilled over a sand-bath at $200^{\circ}$ into a saturated solution of dimedon. According to Neuberg, acetaldomedon is hydrolysed by boiling water, whereas formaldomedon is resistant and only hydrolysed by acid. Klein and Werner claimed that by this method formaldomedon distilled over from the mixture and was reprecipitated as formaldomedon in the container.

We repeated this procedure a number of times with uniformly unsuccessful results. In no case did any formaldehyde pass over and become precipitated in the container. In order to see whether any hydrolysis did in fact take place or whether our experimental conditions were possibly not correct, pure formaldomedon was prepared and treated in the same way. Here again, no formaldehyde passed over and the product appeared to be quite resistant to hydrolysis by phosphoric acid. Nor were we able to confirm Neuberg's statement that acetaldomedon is hydrolysed by boiling water. It may be mentioned in passing, that with the distillation method employed by Klein and Werner, unless very great care is exercised, sucking-back takes place and the retort explodes.

We therefore modified Klein and Werner's method of separation. It was found by treating mixtures of formaldomedon and dimedon with boiling water that these two products could be quantitatively separated. The dimedon passed into solution and could be filtered off and the formaldomedon was left as an insoluble residue. Applying this method the following results were obtained.

(1) Plants exposed to light in a nutrient solution together with sodium bicarbonate and dimedon; an examination of the external solution revealed the presence of a small amount of formaldomedon, M.P. 180-185.

(2) Plants left in the dark with dimedon and sodium bicarbonate; no formaldomedon or acetaldomedon produced, dimedon entirely recovered.

(3) Nutrient solution plus sodium bicarbonate and dimedon exposed to the light, but no plant present; a small amount of formaldomedon produced.

(4) As (3), but the solution placed in the dark; dimedon entirely recovered, no formaldomedon formed.

The effect of anaesthetics was also investigated. Plants were allowed to assimilate in the presence of phenylurethane and potassium cyanide. In solutions of these narcotics of strength $0 \cdot 1$ to $0.0005 \%$ no visible assimilation was found to occur, but our solutions, contrary to the statements made by Klein and Werner, still yielded formaldomedon at the end of the experimental time.

An attempt was also made to see whether any formaldomedon was deposited within the tissues of the Elodea. Cut shoots were allowed to assimilate 
in the presence of dimedon for $6-8$ hours. The tissues were now rubbed up with $1 \mathrm{~g}$. of lead acetate and $3 \mathrm{~g}$. of barium hydroxide, according to the details given by Klein and Werner, so that the mixture was strongly alkaline. $100 \mathrm{cc}$. of water were added and the whole allowed to stand for 24 hours. At the end of this time, the solution was filtered, acidified with hydrochloric acid, shaken with the precipitate that had formed and again filtered. The solution was finally extracted with light petroleum in the manner described above and evaporated under reduced pressure. Although this experiment was repeated some ten or fifteen times, in no case could we find a trace of either dimedon or formaldomedon in the extract.

\section{Discussion.}

It will be seen from these results that the production of formaldomedon in the external solution surrounding the plant is no criterion that formaldehyde is the first product of photosynthesis in the living plant. Bicarbonate solutions in the presence of light produce appreciable amounts of the aldehyde and this process is independent of the assimilation mechanism of the plant. Our results therefore indicate that in aqueous solutions of either bicarbonate or carbon dioxide the following equilibrium exists:

$$
\mathrm{CO}_{2}+\mathrm{H}_{2} \mathrm{O} \rightleftharpoons \mathrm{H} \text {. } \mathrm{CH}: \mathrm{O}+\mathrm{O}_{2} .
$$

In the presence of such a substance as dimedon, which removes formaldehyde from the system as an insoluble precipitate as soon as it is formed, the equilibrium is pushed towards the right half of the equation. Furthermore, the fact that, unlike Klein and Werner, we were still able to detect the presence of formaldomedon in the external solution in the presence of anaesthetics such as phenylurethane, which suppresses all visible assimilation, shows very clearly that the production of formaldehyde in these circumstances has no connection with the photosynthetic process in the living plant.

The experiments carried out by Klein and Werner on land plants, in which the dimedon was conducted to the assimilating cells via the transpiration stream, have not been repeated by ourselves. These workers have put forward the claim that in all cases they were able to isolate formaldomedon from leaves exposed to light. This experimental work, however, is open to the strong objection that dimedon undoubtedly exerts a marked toxic action on the plant, and Klein and Werner themselves admit that its presence caused the stomata to close. It may well be on this account that, if any formaldehyde were produced, it would be a direct product of decomposition processes taking place in the living cell due to the toxic action of the dimedon. It is a well-known fact that the decomposition of the chlorophyll pigments can, in certain circumstances, give rise to formaldehyde; a result which has led some investigators to make the claim that this is proof that formaldehyde is a product of assimilation, whereas in reality they have been dealing with a decomposition by-product. Lastly, it will be remembered that we were unable to find any trace of formaldomedon in the leaves of Elodea. 
Although the formaldehyde hypothesis has the merit of simplicity, which has probably been the prime cause of its wide popularity, no work has as yet convincingly shown that formaldehyde is produced normally in the green leaf or that it plays any part in the photosynthetic process of the living plant.

\section{SUMMARY.}

The claim made by Klein and Werner to have shown by the use of dimedon that formaldehyde is the first product of photosynthesis has been re-investigated. It is shown that there is no experimental foundation for this statement, and that the production of formaldehyde in their solutions is due to the action of light on carbon dioxide and bicarbonates and is independent of the photosynthetic mechanism of the living plant.

\section{REFERENCES.}

Baker (1913). Anns. Bot. 27, 411.

Baly (1921). J. Chem. Soc. 119, 1025.

- (1927). Proc. Roy. Soc. Lond. A 116, 212.

- (1929). Proc. Roy. Soc. Lond. A 122, 393.

Barton-Wright (1930). Recent advances in plant physiology. (J. and A. Churchill.)

Boitreux (1920). Comp. Rend. Soc. Biol. 83, 737.

Bokorny (1891). Ber. deutsch. chem. Ges. 24, 103.

Grafe and Vieser (1909). Ber. deutsch. bot. Ges. 27, 431.

(1911). Ber. deutsch. bot. Ges. $29,19$.

Klein and Werner (1926). Biochem. Z. 168, 361.

Loew (1889). Ber. deutsch. chem. Ges. 22, 482.

Moore and Webster (1920). Proc. Roy. Soc. Lond. B 91, 196.

Vorlander (1893). Liebig's Ann. 173, 1063. 